\title{
La nuit sacrée: figurações de espelhamento no filme de Nicolas Klotz
}




\section{Resumo}

O objetivo deste artigo consiste em examinar a transposição intersemiótica de algumas figurações de espelhamento no filme de Nicolas Klotz, La nuit sacrée (1993), baseado nos dois romances L'enfant de sable (1985) et La nuit sacrée (1987), do autor marroquino Tahar Ben Jelloun, e em salientar as distorções resultantes desta transmutação. Baseado, em primeiro lugar, na teoria semiótica formulada por Ignacio Assis Silva, em Figurativização e metamorfose: o mito de Narciso, tentei analisar a integração dos constituintes narrativos: vida--paixão - morte e metamorfose, nos dois textos literários e na adaptação cinematográfica.

\section{Palavras-chave}

literatura e cinema, intertextualidade, transmutação, figurações de espelhamento, metamorfose

\section{Abstract}

This article aims at examing the inter-semiotic transposition of some figurations of reflection in the movie by Nicolas Klotz, La nuit sacrée (1993), based on the novels L'enfant de sable (1985) and La nuit sacrée (1987), by the Moroccan writer Tahar Ben Jelloun, and pointing out the distortions caused by this transmutation. Primarily based on the semiotic theory defined by Ignacio Assis Silva, in Figurativização e metamorfose: o mito de Narciso, I have tried to analyze the integration of the narrative constituents: life - passion - death and metamorphosis, in the two books and in the film adaptation.

\section{Key words}

literature and cinema, intertextuality, transmutation, figurations of reflection, metamorphosis 
NARCISSE

$$
\begin{array}{r}
\text { à } \\
\text { la } \\
\text { gloire } \\
\text { de } \\
\text { Narcisse } \\
\text { qui } \\
\text { sut } \\
\text { embrasser } \\
\text { l'eau } \\
e t \\
\text { donner } \\
\text { sans } \\
\text { cesse } \\
\text { son } \\
\text { image }
\end{array}
$$

Alain Rivière, 1999.

"Há um livro e, espelhando-se sobre ele, há um filme." 1

T principio, houve um fato: um pai de família árabe, que tinha sete filhas e nenhum descendente masculino, fez votos a Alá para que a oitava criança fosse um menino; nasceu, porém, mais uma filha. Sentindo-se castigado pelo Céu e menosprezado na sociedade, o pai tentou desmentir o caso "vergonhoso" e dispôs, para ocultar a verdade, que o bebê recém-nascido fosse educado como filho primogênito. A ocorrência se fez pública quando "o herdeiro" chegou à idade adolescente.

1. Citação do livro A nave extraviada, de Bernadette Lyra (1995, p. 15), que, aliás, deu origem a este trabalho iniciado na disciplina: Jogos de ecos; simulacro e analogia em filmes contemporâneos, ministrada pela autora do livro, na ECAVUSP, no $1^{\circ}$ semestre de 2000. O objetivo do curso era explorar as configurações do repetitivo no cinema. Enfocaram-se alguns procedimentos figurativos, tais como estereotipagem, equivalência, reiteração, paródia, sátira, e outros, e, sobretudo, as figurações originadas pela repetição, que surgem na teia de jogo entre o filme es 


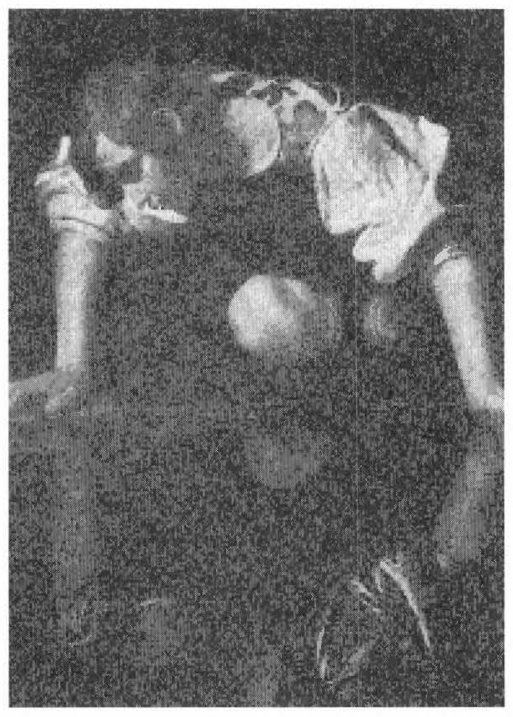

Houve um comentário na imprensa local: um jornalista descobriu o caso, e o redatorchefe considerou o assunto suficientemente insólito para ser divulgado na coluna dos faits divers.

Houve, entre os leitores do jornal, um escritor e sociólogo marroquino, engajado a chamar a atenção internacional para as barbaridades cometidas no mundo árabe tão marcado pelo machismo: Tahar Ben Jelloun. O caso da menina criada como filho primogênito da família inspirou seu sexto romance, escrito em francês e publicado em Paris, L'enfant de sable (1985), e voltou a ser tratado, de modo diferente, em La nuit sacrée (1987), que seria o primeiro livro de um autor maghrébin premiado com o Goncourt.

E há, principalmente, o filme La nuit sacrée (1993), de Nicolas Klotz, que será o objeto de estudo destas páginas. Produzido por FlachFilm, Les Films Ariane, France 3 Cinéma, Titane, com o apoio de Canal +, o longa-metragem, com Amina e Miguel Bosé nos papéis principais, é uma transposição que espelha os dois romances mencionados de Ben Jelloun. O cineasta, porém, introduziu algumas transmutações que dão lugar a uma leitura diferente de sua obra.

$* * *$

Há, aliás, um livro de Bernadette Lyra, A nave extraviada (1995), que elabora as figurações de espelhamento entre o filme Brás Cubas (1985), de Julio Bressane, e as Memórias póstumas de Brás Cubas (1880), de Machado de Assis. Começa por uma série de metatextos do cineasta sobre seu fazer fílmico (os "Paralelos"); segue comentando, no capítulo "Equivalências", a transposição intersemiótica do texto literário para o cinema, e termina com um 
próprio jogo criativo - as "Projeções" - que metamorfoseia o filme de Bressane, Memórias de um estrangulador de loiras (1971), em um poema e em um texto combinatório.

Eduardo Peñuela Cañizal, ao apresentar $A$ nave extraviada, fala de um "duplo labirinto narcíseo", pelo espelhamento do texto machadiano na adaptação cinematográfica e, ao revés, pela transposição de um filme numa forma poética.

Meu interesse particular nesse estudo sobre o filme de Bressane é a mise en pratique de uma teoria sobre um" "jogo de ecos", a transmutação ${ }^{2}$ de um sistema de signos verbais num sistema de significação não verbal.

Confesso, aliás, que qualquer "labirinto narciseo" exerce sobre mim um encanto mágico, seja nos mitos, na literatura ou no cinema, sentindo que "uma espécie de perturbação nos percorre diante de um duplo" (Lyra, 1995:15). E há uma série de textos - espelhos literários ou cinematográficos - que me fascinam pelo fato de refletir a sociedade.

Ao considerar a ocupação com uma obra de arte um jogo que surge entre o jouet e o jogador, abre-se uma nova perspectiva no âmbito da análise, que, ao meu ver, supera a insatisfação da interpretação hermenêutica. Parece-me óbvio que qualquer obra de arte carece de sentido se não houver um ser humano "consumidor". Um filme adquire "vida" pelo espectador; um livro, pelo leitor. ${ }^{3}$

Confesso, porém, que um dos textos clássicos que mais me fascina é o próprio mito de Narciso.

Cabe mencionar aqui o estudo semiótico de Ignacio Assis Silva (1995), Figurativização e metamorfose: o mito de Narciso, que "faz caminho no rumo desse universo de sentido que teima em se esconder no mito de Narciso, nas configurações que ele assume em obras literárias e em textos plásticos 94 e que me abriu os olhos perante a perspicácia do texto ovidiano.

2. Cf. Lyra (1995, p. 16): "Jakobson foi quem primeiro conceituou a tradução intersemiótica, chamando-a de "transmutação' [...]".

3. O autor checo Pavel Kohout, no momento de pronunciar um brinde de agradecimento à anfitriã, num banquete de luxo no hotel Palace de Lucerna, formulou sua pergunta irônica: "Was wäre ein Gastgeber ohne Gast?' ("Que seria um anfitrião sem nenhum convidado?').

4. Eduardo Peñuela Cañizal, no texto introdutório, na capa do livro. 
O objetivo deste trabalho consiste em examinar a transposição intersemiótica de algumas figurações de espelhamento no filme $L a$ nuit sacrée e nos dois romances de Tahar Ben Jelloun, em salientar as deformações resultantes dessa transmutação e em comentar os desvios da nave:

"Há dois livros e, espelhando-se neles, há um filme".

$* * *$

On raconte - mais Dieu est plus savant que nous dès lors qu'il s'agit de dire le vrai sur les événements du passé...

Les mille et une nuits.

Sinopse do filme

La nuit sacrée começa enfocando a personagem principal (Carole Andronico) que, dirigindo-se ao espectador, diz chamar-se Achmed. O suposto jovem encontra-se num souk árabe, que uma câmera subjetiva percorre com rapidez. Achmed nota que é perseguido por um grupo de adolescentes, "por não ser do mesmo bairro", tenta

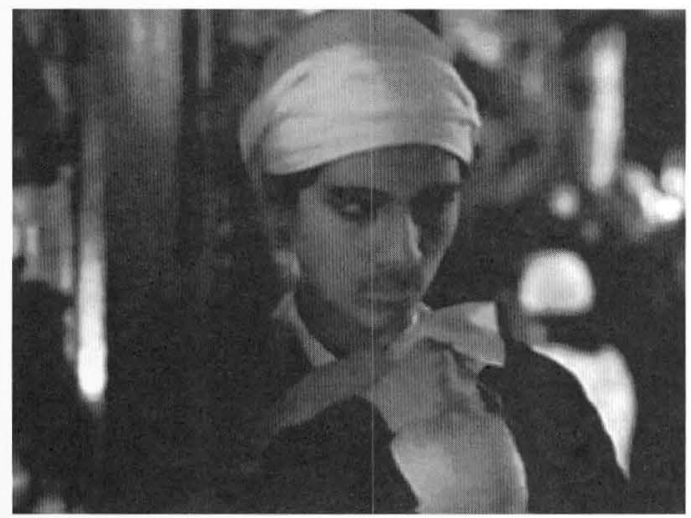

escapar, porém não o consegue e precisa bater-se com eles. Desolado e com lágrimas nos olhos, entra na loja de seu pai (François Chattot), o qual, além de tudo, bate em Achmed porque "homem não chora". Seu irmão (Farid Belkhaya), que presencia a cena, manifesta seu desprezo pelo sobrinho, por não saber defender-se direito, e pressagia que Achmed será a desgraça da casa.

O espectador começa a compreender: a causa verdadeira de não gostar do sobrinho é o fato de que Achmed será o herdeiro único, 
no dia em que seu pai morrer. O tio alimentava a esperança de logo poder enriquecer-se, já que seu irmão doente parecia incapaz de ter filhos; mas depois de ter sete meninas, chegara mais uma menina que, pela decisão do pai, foi criado como o filho "primogênito" tão desejado pela família, e igualmente odiado pelo tio cobiçoso.

Pouco depois, num lugar público, Achmed nota que suas pernas estão manchadas de sangue. Ao chamar a atenção de seu pai, querendo saber o que está acontecendo com seu corpo, esse pega a caçula e leva-a embora, para que ninguém se intere da verdade.

As seguintes cenas mostram a filha (agora interpretada por Amina) numa crise de identidade; porém ela decide aceitar o papel que seu pai the atribuiu, querendo assim aproveitar o máximo possível dos privilégios normalmente reservados aos homens. Adotando logo um jeito machista, começa a tiranizar sua mãe (Jalila Baccar) e as irmãs, força um casamento fictício com Fátima (Carmen Chaplin), a filha paralítica de seu tio, encarrega-se da fábrica de seu pai e empreende viagens de negócios.

Distante da família e sozinha num hotel, a garota experimenta, um dia, sair vestida de mulher. Ao apresentar-se no hall do hotel, com o véu tradicional, passa a ser objeto de desejo de um hóspede solitário. Estaria disposta a aceitar o convite, porém, fica tão perturbada pela situação que desmaia.

Logo depois, no final do Ramadã, seu pai entra em agonia. Chama Achmed, para pedir-lhe perdão e, pouco antes de morrer, abençoando-a, lhe dá um nome feminino: Zahra. Aconselha-lhe a sumir de casa e recomeçar a viver.

Uns dias depois do enterro, Zahra volta ao cemitério, abre o túmulo de seu pai e joga dentro todos os objetos que lembram seu passado de homem. Abandona então sua casa e percorre o país.

Um dia, numa cidade distante, Zahra faz amizade com uma mulher, chamada L'Assise (Maite Nahyr), que cuida de uma casa de banho. Essa lhe oferece sua casa, para que se ocupe do irmão cego, apelido de Cônsul (Miguel Bosé), que, não obstante sua cegueira, é um letrado no Alcorão. Zahra, por entender-se bem com o cego, provoca os ciúmes da Assise. Procurando como afastar essa mulher do lado de seu irmão, a Assise descobre a proveniência de Zahra, 
viaja para a cidade natal dela, onde chega a conhecer o tio cobiçoso. Os dois entendem-se: Zahra precisa desaparecer. Na volta da viagem, a Assise tenta assassiná-la.

Devido a essas circunstâncias, Zahra deixa o Cônsul e sua irmã, e volta para casa. Ali se vê frente a uma situação catastrófica: os bens paternos ficaram completamente arruinados, e sua mãe vive numa demência total. Zahra entra novamente numa crise profunda. Exposta ao ódio de seu tio e vendo cumprida a profecia de que a casa seria arruinada se o suposto "Achmed" fosse o herdeiro, Zahra resolve matá-lo, resolvida a sofrer uma pena de prisão.

Acaba o filme numa panorâmica em plongée sobre uma praça, onde um grupo de homens escuta as palavras de um contador público: é o Cônsul que, andando pelo mundo, narra a história da vida de Zahra.

$$
* * *
$$

So while the Poet stood in this sweet spot, Some fainter gleumings o er his fancy shot; Nor was it long ere he had told the rale Of young Narcissus, and sud Echo's bale.

John Keats.

\section{A construção do objeto-valor}

Não posso dizer se realmente foi instaurado um processo no caso do pai que tinha imposto sua vontade sobre a filha caçula, obrigando-a a adotar o papel do primogênito inexistente. Sabemos, efetivamente, pouco sobre os fatos reais que deram origem a uma série de produções, escritas ou filmadas. Estas, no entanto, encadeiamse perfeitamente, uma ao lado da outra, como num colar, sendo a coluna dos faits divers a primeira pedra, ao lado da qual luzem as duas jóias literárias de Ben Jelloun que, por sua vez, fazem jogo com o brilho mágico do filme de Nicolas Klotz.

É de supor que a vítima do caso real apenas se reconhecesse nas elaborações artísticas, porque o modo de construir o objeto-valor - uma biografia fascinante para essa garota, forçada a adotar um 


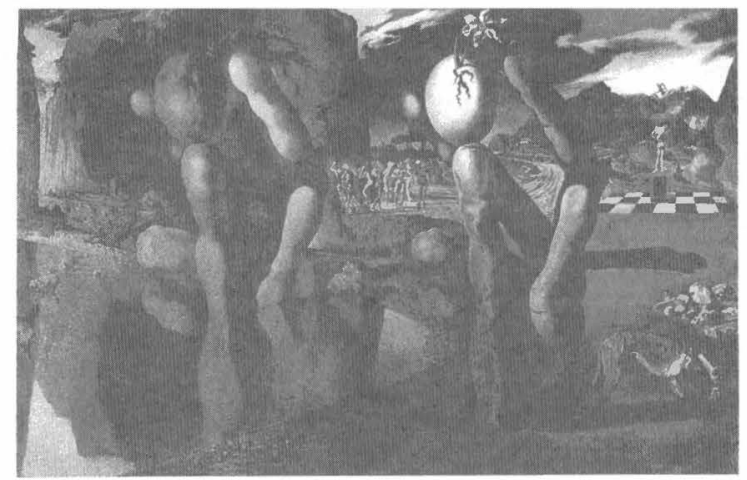

na criação artística: papel que não lhe corresponde espelha, nos três gêneros de texto $(o$ jornalístico, o literário e o cinematográfico), os desejos e as paixões do respectivo autorsujeito, demiurgo

Et creavit Deus hominem ad imaginem suam:

ad imaginem Dei creavit illum $[\ldots]^{5}$

Pergunto-me, entre parênteses, até que ponto antecipa o próprio versículo bíblico, em forma de quiasmo, as teorias semióticas sobre a construção de objeto-valor; Ignacio Assis Silva (1995: 84), ao resumi-las em seu livro sobre o mito de Narciso ${ }^{6}$, cita Greimas \& Fontanille que opinam que "on pourrait dire, en quelque sorte, que dans cette affaire, sujet et objet se choisissent réciproquement [...]".

Sendo crucial a relação entre autor e obra, varia - devido à intenção do criador - o grau de presença de sua imagem no objeto criado. É óbvio, por exemplo, que o autor de um boletim de ocorrência ou um artigo científico propõe-se a enfocar um acontecimento de um modo objetivo. No entanto, um autor precisa decidir-se, a cada instante, pela escolha e pelo enfoque do objeto referencial, sabendo que qualquer triagem, qualquer ponto de vista implica manipulação.

É certo, porém, que a literatura e o cinema de arte ganham seu encanto particular pela presença mágica do sujeito-criador; a diegese passa para o segundo plano. Portanto, não surpreende que L'enfant de sable comece pelo código da ficção por excelência: " $I l y$

5. Gênesis, 1, 27.

6. Cf. o capítulo: "Construçāo do sujeito - construção de objeto: simetrias?" 
avait" e termine pela declaração que "les mythes et les légendes sont plus supportables que la stricte réalité”.

O teórico Michael Riffaterre, em Littérature et réalité, formula claramente que "le lecteur qui essaie d'interpréter la référentialité aboutit au non-sens"'(In: Barthes, 1982:94). E não faz sentido nenhum discutir a biografia da protagonista de L'enfant de sable e de La nuit sacrée - versão literária e cinematográfica. Qual seria "a verdadeira"?

Tanto nas obras de Ben Jelloun como no filme de Nicolas Klotz está nitidamente visível a imagem do autor, com seus desejos, suas intenções, suas frustrações. Narciso inclina-se sobre a superfície da água, e Ovídio sabe:

Fons erat inlimis, nitidis argenteus undis (Ovidi Metamorphoseon libri, III, 408).

A nitidez da água ("undce nitidce") ocasiona o reflexo, e a pureza ("fons inlimis") permite também ver o fundo. $\mathrm{O}$ artista, frente a sua obra, vê-a com toda sua implicação e, ao mesmo tempo, vê seu próprio traço. A situação lembra o Narciso atribuído a Caravaggio que apresenta o homem e sua imagem; falta, porém, o Narciso-flor, tal como ele está presente, por exemplo, no quadro Metamorfosis de Narciso (1936/37), de Salvador Dalí.

$$
* * *
$$

La Mort d'Orphée: "Vous cherchez trop à comprendre ce qui se passe, cher Monsieur. C'est un grave defaut." Jean Cocteau.

\section{"Je suis l'autre?"}

Em princípio, cada relação pai-filho implica um espelhamento ou, pelo menos, no desejo do pai de ver sua imagem rejuvenescida - no outro. Como as regras de uma sociedade árabemachista atribuem um valor inferior às mulheres, um homem sem descendência masculina está exposto a perder sua consideração pública de um representante do sexo forte, podendo mesmo ser considerado como efeminado: os filhos - ou, como em nosso caso, as filhas - representam seu espelho. Esse medo deve ter levado o pai de nossa história a transverter a menina caçula em filho 


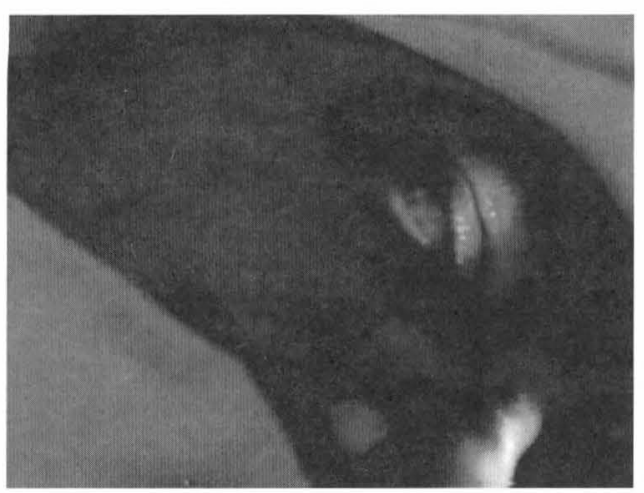

"primogênito", dandolhe o nome de Achmed: "o (homem) que merece louvores". Esse enredo repre-ensivo, porém, origina a tragédia que só se resolve pela morte. Achmed é uma imagem falsa; e é preciso que o espelho quebre, que o Destino reinstale 0 equilíbrio. O pai libera a caçula de seu destino forçado numa "noite sagrada", no momento de sua morte. No filme, uma voz feminina, em off ${ }^{7}$, comenta as circunstâncias:

Ce fut au cours de cette nuit sacrée, la vingt-septième du mois du ramadan, quand les Anges et l'Esprit descendent, avec la permission de leur Seigneur, pour régler toute chose, que mon père, alors mourant, me convoqua à son chevet. $C$ 'est aussi la Nuit de l'Innocence, la nuit des enfants, mais les enfants ne sont pas innocents. Ils sont même terribles. ${ }^{8}$

Pedindo perdão, o pai devolve à filha sua identidade feminina, abençoa-a e dá-lhe o nome de Zahra, que significa "princesa":

"Tu viens de naître cette nuit... Tu es une femme... Laisse ta beauté te guider. Il n'y a plus rien à craindre."

7. Uso esse termo por ser de senso comum, sabendo que é impreciso: uma voz não pode ser off.

8. Cf. Ben Jelloun: Ce fut au cours de cette nuit sacrée, la vingt-septième du mois de ramadan, nuit de la "descente" du Livre de la communauté musulmane, où les destins des êtres sont scellés, que mon père, alors mourant, me convoqua à son chevet et me libéra. II m'affranchit comme on faisait autrefois avec les esclaves. Nous étions seuls, la porte verrouillée. II me parlait à voix basse. La mort était là : elle rôdait dans cette chambre à peine éclairée par une bougie. A mesure que la nuit avançait, la mort se rapprochait, emportant peu à peu l'éclat de son visage. [...] C'était la nuit des enfants. [...] "Les Anges et I'Esprit descendent durant cette Nuit, avec la permission de leur Seigneur pour régler toute chose." C'est la Nuit de l'Innocence, mais les enfants ne sont point innocents. I/s sont même terribles.(Ben Jelloun, 1987, pp.2223) 
A fala do pai, no filme, continua em árabe, o que cria um clima de estranheza. Trata-se, ao meu ver, de uma fórmula religiosa, que corresponde à frase contígua no texto básico: "La Nuit de Destin te nomme Zahra [...]".(Ben Jelloun, 1987, p. 32)

Je t'adore, sous ces myrtes, ô l'incertaine Chair pour la solitude éclose tristement Qui se mire dans le miroir au bois dormant.

Paul Valéry.

Sobre espelhos e livros

Nos livros de Ben Jelloun, os espelhos são tópicos e remetem ao ato narrativo. Sua função não consiste em agradar, senão - citamos ao próprio autor - em "perturbar" e "trair":

La trahison se situe quelque part dans cette mise en place d'un faux-miroir. Trahir, c'est cela: perturber la lassitude, inquiéter le lac tranquille de nos certitudes.(Cf. Salha,1993, p. 94)

Porém, o espelho também agrada: veja o comportamento de Achmed-Zahra num quarto de hotel trancado:

Je m'étendis sur le lit, nue, et essayai de redonner à mes sens le plaisir qui leur était défendu. Je me suis longuement caressé les seins et les lèvres du vagin. J'étais bouleversée. J'avais honte. La découverte du corps devait passer par cette rencontre de mes mains et de mon bas-ventre. Doucement mes doigts effleuraient ma peau. J'étais tout en sueur, je tremblais et je ne sais pas encore si j'avais du plaisir ou du dégoût. Je me lavai puis me mis en face du miroir et regardai ce corps. Une buée se forma sur la glace et je me vis à peine. $J$ 'aimais cette image trouble et floue : elle correspondait à l'état où baignait mon âme. Je me rasai les poils sous les aisselles, me parfumai et me remis au lit comme si je 
recherchais une sensation oubliée ou une émotion libératrice. Me délivrer. (Ben Jelloun, 1987, pp. 115-116)

Esta cena lembra o arquitex to ovidiano ${ }^{9}$, que descreve o ardor de Narciso frente ao corpo espelhado: deitado ("humi positus"), ele se admira ("adstupet ipse sibl"), se deseja ("se cupit"), provoca agrado ("probat"), se procura ("petit") e fica apaixonado ("et ardet") por si mesmo, sem parar de beijar ("quotiens dedit oscula") seu próprio objeto de desejo.

À diferença de Narciso, Achmed procura, no reflexo do espelho, sua verdadeira identidade, ou seja, a imagem feminina. $O$ autor precisa: “Ce que je demande à l'écriture, cen'est pas qu'elle me renvoie mon image, mais qu'elle me parle d'un territoire du lointain que je ne soupçonne pas".(M'Henni, 1993, p. 84)

O espelho que remete um reflexo diferente, cria uma tensão entre ser e parecer; a verdade, paradoxalmente, aparece no espaço imaginário. "It is the face of my soul", exclama Dorian Gray. (Wilde, 1990, p. 157)

\section{O desequilíbrio} entre a aparência e a imagem verdadeira causa um conflito trágico que só se soluciona na catástrofe. A oposição entre o Narciso-homem e seu reflexo reconcilia-se na morte e na metamorfose em Narciso-flor.

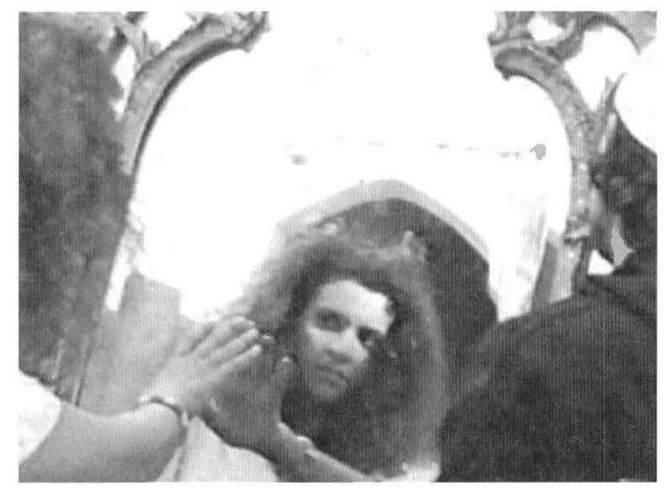

9. Metamorphoseon liber, III, 418-427:

adstupet ipse sibi vultuque inmotus eodem hæret, ut e Pario formatum marmore signum. spectat humi positus geminum, sua lumina, sidus, et dignos Baccho, dignos et Apolline crines, inpubesque genas et eburnea colla, decusque oris et in niveo mixtum candore ruborem cunctaque miratur, quibus est mirabilis ipse. se cupit inprudens et, qui probat, ipse probatur, dumque petit, petitur pariterque accendit et ardet. inrita fallaci quotiens dedit oscula fonti! 
$\mathrm{Na}$ "noite sagrada", quando o pai aceita seu destino que vai morrer sem filho herdeiro, Achmed deixa de existir, metamorfoseando-se em Zahra: "La Nuit du Destin te nomme Zahra, fleur des fleurs". (Ben Jelloun, 1987, p. 32)

Além de abrir o jogo com o mito clássico, Ben Jelloun estabelece explicitamente uma equivalência entre corpo e texto:

Ces caresses devant le miroir devinrent une habitude, une espèce de pacte entre mon corps et son image, une image enfouie dans un temps lointain et qu'il fallait réveiller en laissant les doigts toucher à peine ma peau. J'écrivais avant ou après la scéance. J'étais souvent à bout d'inspiration, car je découvris que les caresses accompagnées d'images étaient plus intenses. Je ne savais pas où aller les chercher. J'avais beau en inventer quelques-unes, il m'arrivait de rester en panne, comme il m'arrivait aussi de rester des heures devant la page blanche. Mon corps était cette page et ce livre.(Ben Jelloun, 1985, p. 116).

O livro como o corpo espelhado - esse jogo tem tradição: Marguerite Duras usa o mesmo procedimento logo no começo de seu best-seller L'Amant. A narradora, ao contemplar no espelho o envelhecimento de seu rosto, compara implicitamente suas rugas às líneas de uma página:

Ce vieillissement a été brutal. Je l'ai vu gagner mes traits un à un, changer le rapport qu'il y avait entre eux, faire les yeux plus grands, le regard plus triste, la bouche plus définitive, marquer le front de cassures profondes. Au contraire d'en être effrayée j'ai vu s'opérer ce vieillissement de mon visage avec l'intérêt que j'aurais pris par exemple au déroulement d'une lecture.(Duras, 1984, p. 10) ${ }^{10}$

Em síntese: a narrativa de Tahar Ben Jelloun, embora sendo arraigada numa tradição árabe, abre o jogo de equivalências com textos

10. Compare-se também o prólogo do filme L'Amant, de Jean-Jacques Annaud, que pöe em jogo a pele humana e uma folha de um caderno de anotações. 
- clássicos e modernos - da literatura européia. A passagem citada de L'enfant de sable legitima, a meu ver, a comparação do texto com o mito clássico.

Resta a análise da transposição dessas passagens literárias para o filme, e veremos: o caminho é outro; extravia-se a nave.

Ах, если ты не Нарцисс, то, свой лик отражённый увидев, О незнакомец - дрожу - новый ты станешь Нариисс.

Вячеслав ИВАНОВ. ${ }^{11}$

"Sim, são para se ter medo, os espelhos."

A figuração do espelhamento, retomada no filme, apresentase de uma maneira diferente. Nicolas Klotz não adaptou para o cinema a cena de Achmed-Zahra frente ao espelho comentada; e não faz mesmo sentido lembrar, num filme, a equivalência estabelecida entre corpo e livro, sendo os dois objetos de leitura.

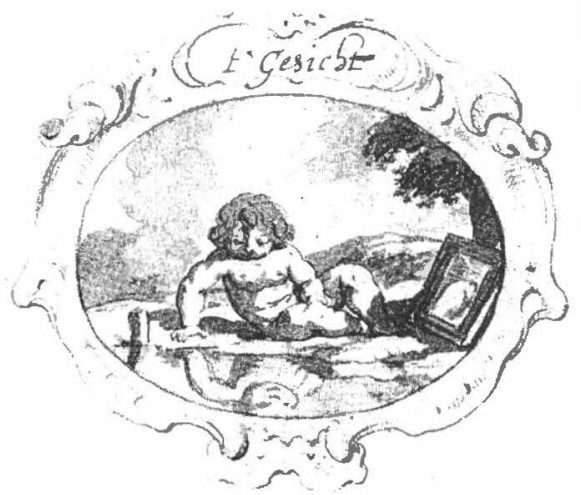

O espelho, porém, na tradição pictórica, é uma representação alegórica do primeiro dos cinco sentidos: a visão. A filologista AlmutBarbara Renger, publicou, em seu livro Mythos Narziss, um desenho dos cinco sentidos, de Cornelis Danckerts. A alegoria da visão (legendada, em alemão, pelo termo ambíguo Gesicht, que significa também "rosto"), que data do século XVIII, mostra um menino, com um espelho de lado, contemplando-se na água da fonte.

11. "Ah, se você não é Narciso, então, ao ver seu rosto refletido, Oh desconhecido - temo - você será um novo Narciso."

Vač eslav Ivanov - Narciso. 
Já que no cinema, a visão é o principal dos sentidos, o mito de Narciso pode adquirir, a este respeito, uma função emblemática.

Nicolas Klotz introduziu uma cena-chave, que não tem correspondência nos dois romances de Ben Jelloun: o Cônsul compra de um vendedor ambulante, na rua, um espelho barroco, suntuosamente emoldurado; os garotos da Escola de Alcorão e outras pessoas ajudamno a levá-lo para casa. Ali, o cego toca com as mãos o objeto adquirido, no momento em que aparece, no espelho, a imagem de Zahra. Os gestos carinhosos, destinados ao próprio objeto, parecem tocar o corpo da mulher desejada. O Cônsul, sendo cego, não vê o que acontece, e a cena cria uma oposição entre ver versus não-ver.

Conforme o vaticínio de Terésias, Narciso chegaria só a uma idade avançada "si se non noverit" (Metamorphoseon liber, III, 348), "se não se conhecer". O auto-reconhecimento implicaria morte e metamorfose. Sendo cego, o Cônsul não consegue ver nem a si mesmo, nem ao outro, o verdadeiro objeto de seu amor: Zahra.

Ela, ao aproximar-se, olha o espelho com desconfiança, e parece que sua própria imagem lhe inspira medo. Não obstante, estende sua mão, e a retira, assustada, como se tivesse tocado um objeto dotado de poderes mágicos. "Sim, são para se ter medo, os espelhos", escreve Guimarães Rosa. (Em: Silva, 1995, p.113)

Além de Zahra, aparecem, no espelho, as pessoas que assistem à cena: as crianças e as outras pessoas que rodeiam o Cônsul. Atam, finalmente, o novo enfeite da casa a uma corda, para subi-lo ao terraço. $\mathrm{Na}$ subida, o espelho reflete os assistentes. O objeto, destacado pela moldura dourada, e ainda enfocado em contre-plongée, aparece, na tela, como se refletisse os espectadores da sala. O próprio filme parece refletir o mundo real: o espelho transforma-se, frente ao espectador, numa "imagem" do próprio filme.

Resumindo: Nicolas Klotz, ao adaptar os textos de Ben Jelloun para o cinema, entra também em diálogo com o mito de Narciso, portanto não com a idéia de encaixar-se numa tradição árabe. O espelho adquire o valor alegórico do próprio filme, dotado de uma força mágica para transformar a sociedade, ao ver-se refletida nele: "si se noverit". Neste sentido, o cineasta é representante de um cinema engagé. 


$$
* * *
$$

Ts'ui Pên diria una vez: Me retiro a escribir un libro. Yotra: Me retiro a construir un laberinto. Todos imaginaron dos obras; nadie pensó que libro y laberinto eran un solo objeto.

Jorge Luis Borges.

\section{O enfoque narrativo}

Tahar Ben Jelloun aplica uma técnica narrativa oriental: os narradores, em ambos os livros, são vários "conteurs", numa praça de Marrakesh, que contam ao público - sendo pagos por isso - a história de Achmed-Zahra. No primeiro romance, apresentam-se alguns contadores, fascinados pelo caso de Zahra - entre outros um "troubadour aveugle", acompanhado de uma mulher jovem, procedente de Buenos Aires ${ }^{12}$. No segundo, trata-se de uma mulher velha que, chegando à cidade, manifesta um interesse particular por essa história. Comportando-se como intrusa num mundo geralmente reservado aos homens, senta-se na halqa $a^{13}$ para apresentar "a versão verdadeira". O relato autobiográfico pressupõe que a velha contadora é Zahra.

O enfoque narrativo usado por Ben Jelloun é uma mise em abyme de sua própria narrativa. O fazer do escritor-Narciso reflete-se no tradicional código oral da halqa, onde Zahra "parle aujourd'hui d'une époque lointaine" (Ben Jelloun, 1987, p. 20), equiparando a palavra escrita à falada.

O autor marroquino alista-se - além da européia - na tradição de Mil e uma noites, tanto pelas técnicas de encaixamento de um elemento no outro e espelhamento do ato narrativo, como também pela mudança de sexo entre o eu, masculino do autor, e o feminino da narradora. ${ }^{14}$

No filme, restou só a cena final que lembra o enfoque narrativo do modelo literário. Na transposição intersemiótica, Nicolas Klotz favoreceu um procedimento diferente, substituindo, no prólogo do

12. Jorge Luis Borges, de fato, esteve no Marrocos, acompanhado de Maria Kodama (depoimento da esposa de Borges ao autor destas líneas).

13. Círculo do contador. Veja o estudo de Rachida Saïgh Bousta (1993, pp.119-129).

14. Cf. a lirica medieval hispano-árabe: na maioria das chamadas jarchas, cujo autor sempre é um homem, o eu-poético é uma mulher que se dirige ao homem amado. 
filme, a praça de Marrakesh por outro espaço tópico do mundo árabe: o souk. Uma câmera na mão ${ }^{15}$ percorre o labirinto do mercado, convertendo assim o espectador numa pessoa que observa, que vê, ao contrário do romance, que deixa o leitor na posição de quem está escutando. ${ }^{16}$ Além disso, a diegese do filme é linear, embora nos romances, o caso de Zahra se apresente em flash-back.

O romance La nuit sacrée começa pela frase: "Ce qui importe, c'est la vérité", propondo um programa narrativo, que consiste em "dizer a verdade". A abertura do filme, porém, enfoca uma pessoa jovem que se apresenta ao espectador pelas palavras: "Je suis Achmed", abrindo, deste modo, um jogo de eco que ironiza o programa narrativo do romance: o espelho do filme é mentiroso.

Cria-se assim uma série de oposições: halqa vs. souk, ouvir $v s$. ver, recordar vs. assistir, estável vs. móvel, verdade vs. mentira.

Os caminhos literários e cinematográficos bifurcam-se.

$$
* * *
$$

É que Narciso acha feio o que não é espelho. Caetano Veloso.

\section{O enfoque trágico}

Referente ao mito ovidiano, Ignacio Assis Silva (1995, p. 123) distingue quatro momentos na história de Narciso: vida - paixão (no sentido comum, bíblico e semiótico) - morte-metamorfose.

No nível diegético, trata-se de uma história de um fracasso do protagonista. Por outra parte, o texto conta uma realização: a probatio

15. Bernadette Lyra (1995, p. 67), no capítulo "Câmera na mão", escreve:

No nivel operatório de imitação do olhar, a posição da câmera situa-se à altura dos olhosde um adulto, tentando a fixação analógica de um angulo de visão humana. A câmera na mão permite o deslocamento abaixo ou acima desse nível. Libertada, a câmera pode rastejar pelo corpo abaixo ou ir além da cabeça. Além disso, a câmera consegue registrar os sobressaltos e os deslocamentos a que está sujeito o seu portador. Como um prolongamento do corpo, como um olho na mão, móvel e sensivel, a câmera palpita, tomada pela proximidade do gesto humano tão próximo.

16. Numa entrevista sobre o premio Goncourt (reportagem gravada no vídeo Itinéraires, Paris, Hachette, 1992), Ben Jelloun disse que costumava ler seus textos em alta voz, para que sua mãe - analfabeta - escutasse os livros. 
do vaticínio de Tirésias e o cumprimento do programa narrativo, que consiste em "falar das formas que se mudaram em novos corpos":

in nova fert animus mutatas dicere formas

corpora [...](Metamorphoseon liber, I, 1-2).

No texto de Ovídio, a profecia do vate é hipotética: Narciso morrerá jovem se "se conhecer". O elemento fatal que provoca o cumprimento da predição é o com-portamento sobranceiro ${ }^{17}$ do belo jovem, a "hybris", que - no pensamento clássico - provoca a vingança do Céu:

"sic amet ipse licet, sic non potiatur amato!" dixerat. adsensit precibus Rhamnusia iustis.(Metamorphoseon liber,III,405-406).

Numa leitura mítica dos romances de Ben Jelloun, Zahra não fica submetida a nenhuma profecia, nem provoca a ira do Céu. Ao comparar a línea diagramática de sua existência com o destino de Narciso, constatamos uma correspondência em unicamente três constituintes narrativos: vida, paixão e metamorfose; falta o sintagma da morte.

$\mathrm{Na}$ "noite sagrada", porém, morre o pai da protagonista. "Le corps mourant, celui du père, et le corps qui vient de naître, celui de la fille", comenta Rachida Saïgh Bousta. (Em M'Henni, 1993, p. 129).

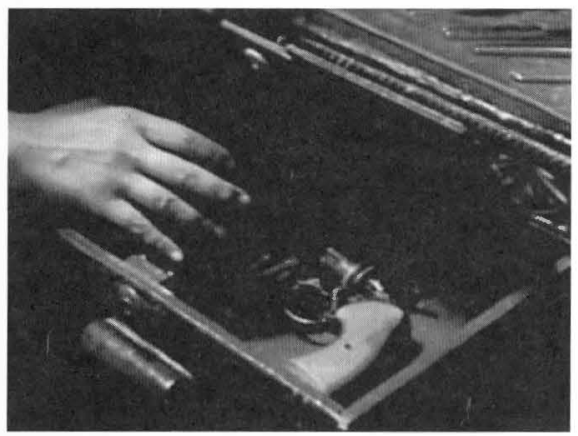

A paixão de Zahra - no sentido da passio bíblica constitui um elemento basilar no romance La nuit sacrée. Condenada pelo assassinato de seu tio a uma pena de prisão, a protagonista fica, além de tudo, exposta a um ato de vingança por parte das irmãs, descritas como "une secte de soeurs musulmanes, fanatiques et brutales" (Ben Jelloun, 1987, p.157) que a acusam de "usurpation et de vol":

17. Narciso rejeita todos seus pretendentes - masculinos e femininos (cf. nossa citação no início do capítulo), o que provoca a desforra de Némesis ("Rhamnusia"), deusa justiceira e vingativa. 
Elles me déchirèrent mon saroual et levèrent mes jambes en l'air. La gardienne, habituée des lieux leur indiqua deux crochets au plafond. Elle leur fournit les cordes. Mes jambes écartées étaient tirées par les cordes de chaque côté. L'aînée me mit um chiffon mouillé dans la bouche. Elle posa sa main gantée sur mon bas-ventre, écrasa de ses doigts les lèves de mon vagin jusqu'à faire bien sortir ce qu'elle appelait "le petit chose", l'asper-gea d'un produit, sortit d'une boîte métallique une lame de rasoir qu'elle trempa dans l'alcool et me coupa le clitoris. En hurlant intérieurement je m'évanouis.(Ben Jelloun, 1987, p. 159)

A excisão transforma a vítima numa pessoa assexuada, anulando, assim, a oposição entre masculino e feminino. Esse ato de tortura pode compreender-se, no nível da diegese, como a metamorfose de Achmed-Zahra em um ser neutro e ambíguo.

$\mathrm{Na}$ altura da narração, cria-se uma ambigüidade parecida: o " $j e$ " pronominal, que se refere tanto à contadora como ao narrador, adquire uma função andrógina.

$$
* * *
$$

A versão cinematográfica não retoma essa cena de excisão, limitando-se, ao primeiro ver, a mostrar a vida da protagonista, que termina numa prisão. Sem essa seqüência, o segundo constituinte do fio narrativo - a paixão - fica menos dramático em comparação com a versão literária. E sem os momentos da paixão, nem da morte, não haverá metamorfose final. Aparentemente, a versão cinematográfica não respeita a estrutura dos modelos literários.

Não obstante, o filme mostra, em várias retomadas, "la lame de rasoir": o Cônsul, numa cena de acesso epiléptico, fere-se com a navalha e, numa discussão com sua irmã, ameaça de cortar-se a carótida. A lâmina, no filme, não serve para fazer a barba: sua presença anuncia violação, suicídio e corte.

Embora falte a cena de amputação na diegese do filme, há um corte no nível da enunciação: o cineasta, ao optar em não mostrar a seqüência da tortura, corta um elemento importante do modelo literário, 
deixando assim o espectador em suspense, por não saber qual será o destino de Zahra na prisão.

Por conseguinte, o constituinte da paixão - a amputação do final da história - persiste no nível da narração.

Fica também em suspense o momento da metamorfose - a metamorfose da própria sociedade. No epílogo do filme, o Cônsul filmado por uma câmera subjetiva que posiciona o espectador em sua halqa - formula este atraso social:

"Je vois, ce pays n'est pas changé."

$* * *$

multi illum iuvenes, multae cupiere puellas; sed fuit in tenera tam dura superbia forma: nulli illum iuvenes, nullae tetigere puellae.

Publius Ovidius Naso.

Sobre narcisos, navalhas e olhos cegos

Escritor e cineasta, ambos, mostram as incongruências sociais - cada um com a técnica mais apropriada ao respectivo meio de expressão. Comentamos como Ben Jelloun combina estruturas narrativas árabes com elementos da literatura européia. Cabe examinar ainda o fazer cinematográfico de Nicolas Klotz.

Entre outros, encontramos a figuração do espelhamento nos filmes de Jean Cocteau; e parece mesmo que a sequiência do Cônsul frente ao espelho tem seu modelo direto em Orphée (1949): ambos, o

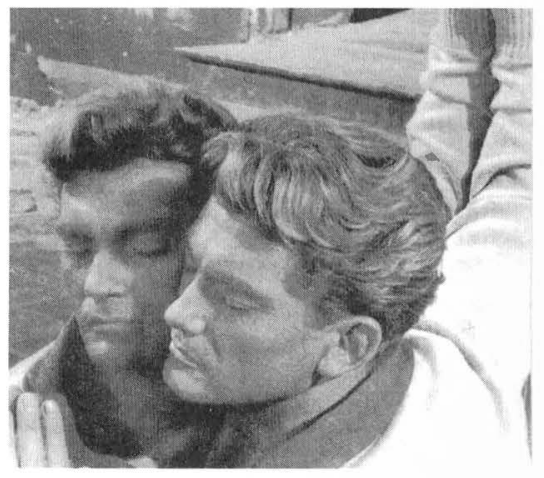
letrado no Alcorão e o príncipe dos poetas aconchegam-se ao vidro do espelho posição comparável.

Embora haja uma semelhança imagética, diferem-se as cenas no nível diegético: Orphée procura no espelho a imagem da Princesa, sem perceber que se trata de uma aparência de sua própria morte. "J'allais oublier 
le thème des miroirs où l'on se voit vieillir et qui nous rapprochent de la mort", comenta Cocteau. ${ }^{18} \mathrm{~A}$ idéia é narcísea: no espelho assoma a morte.

Para o Cônsul, no entanto, o espelho é um mero objeto para apalpar; sem vista também não há reflexo e não existe o espaço virtual ligado à morte. Os infernos situam-se aquém: na própria vida do Cônsul.

\section{$* * *$}

Em outra seqüência de La nuit sacrée, Zahra e a Assise conversam sobre suas vidas respectivas frente a uma geladeira aberta, que está sendo usada como armário; a câmera adota a posição do espelho, colocado dentro da geladeira.

Por um lado, o enfoque realça a função análoga entre espelho e filme: ambos retratam quem tem olho para ver.

O filme, porém, insiste na temática de não ver, pela cegueira do Cônsul, em primeiro lugar, pela mise en scène de uma gaveta com óculos quebrados, e pelo enfoque, em plano de detalhe, do olho distorcido do cadáver do pai, iluminado por uma lâmpada de mão: Zahra abriu o túmulo paterno para depositar, junto com ele, os objetos de sua vida de simulacro, para enterrar "Achmed" ao lado desse corpo sem visão. A imagem repete-se, em flash-back, nos pesadelos da filha e assusta, ao mesmo tempo, o espectador na sala.

$\mathrm{O}$ desconforto transmitido pelo enfoque lembra a seqüência dos asnos mortos encima do piano de cauda ou a famosa cena inicial do olho de vaca cortado, de Un chien andalou (1929), de Luis Buñuel e Saivador Dalí.

Por outro lado, o enfoque inusitado - dentro de uma geladeira - lembra outro filme Buñuel: no prólogo de Ensayo de un crimen (1955), a câmera - atrás do menino Archibaldo - está posicionada dentro de um armário. Além disso, constatamos a presença da navalha, com sua lâmina cortante, nos dois fỉmes: o Cônsul e o Sr. de la Cruz cortam-se ambos na mão: Archibaldo ao fazer a barba, frente a um espelho que duplica a imagem deste "cavalheiro distinto, burguês

18. Cf. o prefácio do roteiro de Orphée (Cocteau, 1950, pp. 5-11). 
bem-apessoado, dedicado à cerâmica e de que, desde o início, se sabe que é dado à volúpia de assassinar" (Lyra, 1993, p. 72). A vista do sangue lembra-lhe a imagem da cabeça (e logo das pernas) da governanta morta. Archibaldo e Zahra, ambos, vêem - numa lembrança de pesadelo - a cabeça de um defunto.

Na seqüência seguinte, Archibaldo está enfocado por uma câmera na posição do espelho.

Ambos, também, na juventude, estão sujeitos ao simulacro da identidade sexual: Zahra, pela imposição de seu pai, e Archibaldo, pela própria vontade:

Travestido com as vestes da mãe, Archibaldo abole a diferença elelela. Igual-se a Hamlet, herói da "tragédia cômica" do mesmo nome, escrita por Buñuel em sua primeira investida teatral, que, exclama: "Niña o doncella, mujer o vieja, vuestra disyuntiva es esa: así que Niño = Niña”. (Lyra, 1993, p. 78)

Reaparece a navalha, em Ensayo de un crimen, quando o protagonista está com a obstinação de assassinar Patricia Terrazas. A vítima seleta pega um copo de leite, na geladeira da cozinha, enquanto Archibaldo está premeditando o crime: o assassino frustrado vê, em sua imaginação, o olho da vítima escolhida e a lâmina da navalha.

Essa seqüência, obviamente, reconstrói o corte de olho de $U n$ chien andalou, que "talha, no caso as superficies visiveis da matéria expressiva, para nos deixar ver a interioridade onde se alojam significâncias que pertencem a uma imaginação que, através de ferida aberta a um significante aparentemente trivial, chega até nós como um rumor, usando o termo de BACHELARD, insituável".(Cañizal, 1993 , p. 33)

$$
* * *
$$

A presença de Buñuel na obra de Nicolas Klotz é patente e, de certa maneira, La nuit sacrée homenageia a obra buñuelina, por exemplo, na transposição da seguinte passagem do texto benjellouniano: 
Zahra, estando sozinha na casa do Cônsul, quer saber mais sobre essa pessoa enigmática e revista seus pertences:

En faisant le ménage dans la chambre du Consul, je me mis à observer les choses et à fouiller de manière discrète les affaires rangées dans l'armoire. Je n'avais jamais ouvert ce meuble. D'un côté il y avait des vêtements soigneusement pliés, de l'autre une série de tiroirs remplis d'un tas de choses : dans le tiroir du haut, plusieurs trousseaux de clés dont la plupart étaient rouillées : des clés anciennes, des clés cassées, des verrous noircis par une couche de poussière laissée par plusieurs graissages, des clous de toutes les formes et de toutes les tailles.

Je fermai doucement ce tiroir et en ouvris un autre au hasard. Là il y avait une vingtaine de montres toutes en marche, mais chacune indiquant une heure différente. C'était une petite usine du temps dont la logique m'échappait. Certaines montres étaient en or, d'autres en argent.

Dans un autre tiroir il y avait toutes sortes de lunettes et de monocles. Des lunettes de soleil, des lunettes de vue, des lunettes vides ou à moitié montées. Au fond il y avait un paquet de feuilles ficelées. C'étaient des ordonnances d'ophtalmologues, des factures d'opticiens, des prospectus publicitaires pour améliorer la vue. Les dates étaient anciennes.

Je continuai ma fouille en essayant d'établir un lien entre les contenus des différents tiroirs. J'en ouvris un autre. Il était tapissé d'un tissu brodé. Plusieurs rasoirs de barbier étaient disposés avec soin, ouverts; leur lame brillait. Dans un flacon, un ceil de mouton nageait dans un liquide jaunâtre. L'cil me regardait. On aurait dit qu'il était vivant et qu'il était là pour surveiller les rasoirs. J'eus un début de nausée et fermai doucement le tiroir.

Ce que j'allais découvrir ensuite me glaça : dans le tiroir du bas, il n'y avait rien. Au moment où j'allais le fermer, je remarquai qu'il était moins profond que les autres. Je l'ouvris 
entièrement, poussai une cloison et $m$ 'apparut un revolver bien astiqué, en parfait état de marche. Il était vide. Trois chargeurs pleins de balles étaient posés en pile.(Ben Jelloun, 1987, pp. 115-116)

Os objetos que Zahra acha no armário não fornecem o esclarecimento desejado, nem para o leitor assíduo, que também tenta de "comprendre le sens de tous ces objets accumulés". 19

Apresentam-se os objetos, que, em parte, carecem de sentido na vida de um cego, na ordem seguinte:

A. Num lado:

Roupas.

B. No outro lado:

Gavetas.

B1. Na gaveta superior:

Objetos de metal:

Bla. Chaves velhas.

B1b. Chaves quebradas.

B1c. Trincos.

Bld. Pregos.

B2. Em outra gaveta:

Relógios.

B2a. Relógios de ouro.

B2b. Relógios de prata.

B3. Em outra gaveta:

B3A. Óculos e monóculos:

B3Aa. Óculos escuros.

B3Ab. Óculos de grau.

B3Ac. Óculos sem lentes.

19. O leitor identifica-se facilmente com a posição de Zahra: "Je m'asssis sur le bord du lit et essayai de comprendre le sens de tous ces objets accumulés. En face de moi, la machine à écrire, un paquet de feuilles blanches, une chemise avec des pages tapées." (Ben Jelloun, 1987, p. 116). 


\section{B3B. Papéis:}

B3Ba. Receitas oftalmológicas.

B3Bb. Faturas de oculistas.

$\mathrm{B} 3 \mathrm{Bc}$. Anúncios publicitários.

B4. Em outra gaveta:

B4A. Navalhas.

B4B. Um olho de carneiro.

B5. Na gaveta inferior:

Nada.

B5'. Na gaveta secreta:

Uma arma:

B5'A. Um revólver.

B5'B. Cartuchos.

Foge de meu propósito analisar aqui a passagem literária, que abre todo um jogo de referências internas com outros trechos do livro, e limito-me a ressaltar os desvios de transposição cinematográfica.

No filme, o armário, onde o Cônsul guarda seus objetos, é tripartido. Zahra começa a revisá-lo pela parte direita, sobre a qual está colocada uma série de sapatos, formando um item adicional. $\mathrm{Na}$ primeira gaveta há óculos de diferentes tipos (B3Aabc.); na gaveta de baixo, Zahra acha uma coleção de relógios velhos (B2.) e uma pulseira, que ela se põe no braço.

O movimento da câmera, que acompanha a mão, vai à esquerda, ao centro do móvel, fechado com um uma cortina vermelha, que se apresenta como um cenário teatral. Ao abrir a cortina, fica visível uma série de navalhas com as lâminas abertas (B4A.).

A câmera continua à esquerda, onde se empilham várias peças do vestuário (A.), porém, em desordem. Zahra acha um lenço seu, que o Cônsul guardava escondido entre a roupa. Na gaveta de baixo, há uma coleção de chaves velhas (B1 abc.).

O olho da câmera vira à direita, até o centro do móvel, onde se guardam, debaixo da prateleira com as navalhas, vários frascos de 
vidro, contendo olhos de um animal (B4B.). A jovem tira da prateleira um dos vidros, examina-o com atenção e coloca-o no "teatro", junto com as navalhas.

Abre a gaveta inferior, na parte central do móvel, que contém vidros e pregos (B1d.) e acha, na gaveta secreta, um revólver (B5'A.).

A disposição cênica nessa seqüência, ao inverter o arranjo como está descrito no romance, diminui a importância da arma e dá uma posição de destaque aos objetos expostos na prateleira vermelha. O vidro com os olhos e as navalhas ficam expostos na parte central do armário, como se fosse o painel principal de um tríptico.

$\mathrm{O}$ altar profano homenageia os dois objetos fundamentais da criação fílmica de Buñuel: o olho e o cut.

No decorrer destas páginas, penetramos - com a ajuda do fio da figuração de espelhamento em La nuit sacrée, em um vasto labirinto com infinitos caminhos e espelhos ${ }^{20}$, que nos lembra, talvez, o palácio

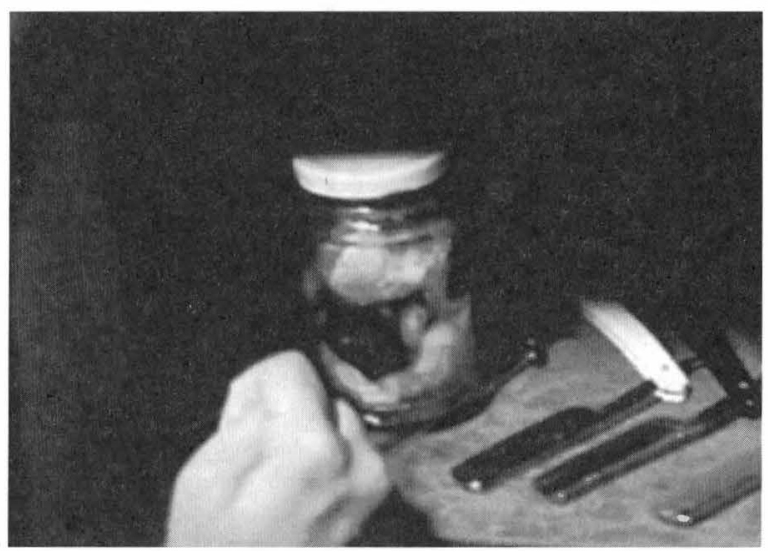

20. Cf. Rachida Saïgh Boustra, 1993, p. 119.

Suite du "jardin aux sentiers qui bifurquent" vers les labyrinthes de l'interdit. La nuit sacrée prolonge directementl'enfant de sable par son articulation explicite surle récit du "Troubadour aveugle". 
do Minotauro ou o Spiegelgarten de Lucerna; e quem ousa entrar, se sente observado, perplexo e surpreendido. Freud descreveria o sentimento pelo adjetivo "unheimlich".

Não achamos, porém, na teia da obra analisada, nenhum reflexo que não transforme seu modelo ${ }^{21}$ : Narciso acreditou num outro na imagem refletida.

O espelho da câmera de Nicolas Klotz atrai pela arte de escolher suas matérias primas, transformando-as num amálgama fílmico de alta qualidade:

nusquam corpus erat; croceum pro corpore florem

inveniunt foliis medium cingentibus albis. ${ }^{22}$

O narciso em flor, com suas pétalas brancas, tem um mito digno de ser lembrado na halqa do cinema.

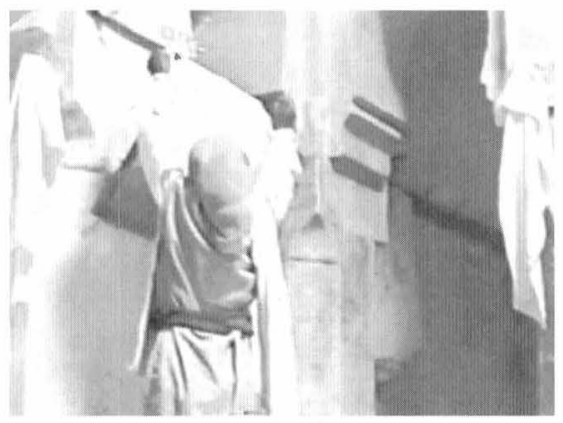

21. Cf. Charles Grivel (1994: 91-92)

Traditionnellement, représenter veut dire doubler le réel d'un spectacle destiné à le faire comprendre et valoir, mettre en vue ce qui pourtant est déjà offert à la vue, redoubler ce dont la perception s'est dans un premier temps saisie, comme s'il ne se remarquait ou entendait pas assez et demandait sur de nouveaux frais et parle détour de la fiction de se manifester ; comme si l'appréhension de premier degré du réel paraissait par le spectacle et la répétition; comme si'l était possible en quelque sorte d'assister substitutivement au réel, en spectateur distant, intéressé mais non concerné. Représenter serait une fois de plus montrer. En fait représenter-cette vue seconde - implique l'engendrement d'un objet pour l'œil : la représentation construit ce que le regard embrasse et en quelque sorte le lui rend. Kracauer remarquait que la représentation filmique a le pouvoir de révéler un monde inédit, invisible, qui se dérobe à la vue, et que le spectacle cinématographique révèle ce dont le spectateur ne saurait être témion.

22. Os últimos versos do mito de Narciso. 


\section{Bibliografia}

BARTHES, Roland et alii. 1982. Littérature et réalité. Paris: Seuil. BEN JELLOUN, Tahar. 1985. L'enfant de sable. Paris: Seuil.

1987. La nuit sacrée. Paris: Seuil.

COCTEAU, Jean. 1950. Orphée. Paris: J'ai lu.

DURAS, Marguerite. 1984. L'Amant. Paris: Minuit.

GRIVEL, Charles. 1994. "La coupe d'images. Buñuel ou l'insoutenable filmique", em LINK-HEER , pp. 91-92.

LINK-HEER, Ursula et alii. 1994. Luis Buñuel: Film - Literatur Intermedialität.Darmstadt, Wissenschaftliche Buchgemeinschaft.

LYRA, Bernadette. 1995. A nave extraviada. Com uma "Apresentação" de Eduardo PEÑUELA CAÑIZAL. São Paulo, Annablume: ECA-USP.

1993. "A morte imaginada", em PEÑUELA CAÑIZAL.

MATURANA, Humberto. 1997. La objetividad: Un argumento para obligar. Santiago de Chile: Dolmen/Granica.

M'HENNI, Mansour (dir.). 1993. Tahar Ben Jelloun: Stratégies d'écriture. Paris: L'Harmattan.

OVIDIUS NASO, Publius. 1977. Metamorphoson libri/ Metamorphosen. Erich Rösch (Hsg.). München: Heimeran, 7. Auflage.

PEÑUELA CAÑIZAL, Eduardo.1993. "O obscuro objeto da ambigüidade", em PEÑUELA CAÑIZAL (org.).

(org.). 1993a. Um jato na contramão: Buñuel no México. São Paulo: COM-ARTE-ECA / Perspectiva.

RENGER, Almut-Barbara. 1999. Mythos Narziss: Texte von Ovid bis Jacques Lacan. Leipzig, Reclam.

SAÏGH BOUSTA, Rachida. 1993. "Béances du récit dans La nuit sacrée”, em M'HENNI, pp. 119-129.

SALHA, Habib. 1993. "Le miroir étoilé : une lecture de la Prière de l'absent de Tahar Ben Jelloun", em M'HENNI, pp. 83-95.

SILVA, Ignacio Assis. 1995. Figurativização e metamorfose: o mito de Narciso. São Paulo: UNESP. 
WILDE, Oscar. 1990. The picture of Dorian Gray. Oxford/New York, Oxford University Press.

\section{Filmografia}

LA NUIT SACRÉE. 1993. Nicolas Klotz.

L'AMANT. 1992. Jean-Jacques Annaud.

ENSAYO DE UN CRIMEN: LA VIDA CRIMINAL DE ARCHIVALDO DE LA CRUZ. 1995. Luis Buñuel.

ORPHÉE. 1950. Jean Cocteau.

ITINÉRAIRES: LANGUE ET CIVILISATION FRANÇAISES PAR

LA VIDÉO. 1992. Paris: Télévision française Antenne 2: Hachette. 